\title{
ON FIXED POINT RESULTS FOR A CLASS OF GENERALIZED MEAN NONEXPANSIVE MAPPINGS
}

\author{
A. A. MEBAWONDU, C. IZUCHUKWU, K. O. OYEWOLE, AND O. T. MEWOMO
}

\begin{abstract}
In this paper, we introduce a new class of generalized mean nonexpansive mappings and propose an iterative algorithm for approximating the fixed points of this class of mappings in the frame work of uniformly convex Banach spaces. We establish some fixed point results for this class of mappings and prove the convergence of the propose iterative algorithm. Finally, numerical experiment is presented to demonstrate the efficiency of our algorithm in comparison with other existing algorithms in literature.
\end{abstract}

\begin{abstract}
Вводиться новий клас узагальнених нерозтягуючих у середньому відображень, для яких пропонується ітераційний алгоритм наближеного знаходження нерухомих точок в контексті рівномірно опуклих банахових просторів. Для цього класу відображень доведені теореми про нерухому точку, а також збіжність зазначеного алгоритму. Шляхом чисельного експерименту наш алгоритм порівнюється 3 відомими.
\end{abstract}

\section{INTRODUCTION}

Banach contraction principle can be seen as the pivot of the theory of fixed points and applications. The theory of fixed points plays an important role in nonlinear functional analysis and is very useful in establishing the existence and uniqueness results for nonlinear differential and integral equations. The importance of Banach contraction principle cannot be over emphasized in the study of fixed point theory and applications, see [6]. Several authors have generalized the well celebrated Banach contraction principle by considering a class of nonlinear mappings and spaces which are more general than the class of contraction mappings and metric spaces (see [3, 10, 26, 27, and the references therein). One of such generalizations of the contraction mapping in the sense of Banach is the well-known nonexpansive mapping. In 1965, Browder [8], Gohde [13] and Kirk [23] gave some existence results for the fixed points of nonexpansive mappings and these were later generalized by other authors (see, [35, 37]).

In 1975, Zhang 44 introduced and studied the class of mean nonexpansive mappings in Banach spaces. He proved the unique existence of fixed points for this class of mappings in Banach spaces with normal structure. For a Banach space $X$ and a nonempty, closed and convex subset $C$ of $X$, we recall that a mapping $T: C \rightarrow X$ is said to be mean nonexpasive if there exist $a, b \geq 0$ with $a+b \leq 1$ such that

$$
\|T x-T y\| \leq a\|x-y\|+b\|x-T y\|,
$$

for all $x, y \in C$.

In 2007, Wu [43] proved that if $a+b<1$, then the mean nonexpansive mapping $T$ has a unique fixed point. Zuo in [46] proved that a mean nonexpansive mapping has approximate fixed point sequence, and under some suitable conditions, he obtained some existence and uniqueness theorems for fixed points of mean nonexpansive mapping.

2020 Mathematics Subject Classification. 47H09; 47H10; 49J20; 49J40.

Keywords. Generalized mean nonexpansive mappings; fixed point; new iterative scheme; strong and weak convergence theorems. 
In 2008, Suzuki 37 introduced a class of mappings satisfying condition $(C)$, called the Suzuki generalized nonexpansive mappings and proved some fixed point results for this class of mappings.

Definition 1.1. Let $C$ be a nonempty subset of a Banach space $X$, a mapping $T: C \rightarrow X$ is said to satisfy condition $(C)$ on $C$, if for all $x, y \in C$,

$$
\frac{1}{2}\|T x-x\| \leq\|x-y\| \Rightarrow\|T x-T y\| \leq\|x-y\| .
$$

In 2010, Nakprasit 29] gave an example of a mapping that is mean nonexpansive but not Suzuki generalized nonexpansive and an example of a mapping that is Suzuki generalized nonexpansive but not mean nonexpansive. He showed that an increasing mean nonexpansive mapping implies Suzuki generalized nonexpansive mapping.

Remark 1.2. We note from the results obtained in [29] that the class of mean nonexpanisve mappings and the class of Suzuki generalized nonexpansive mappings are two different classes of mappings. Thus, it is natural to ask the following question: Can we find a class of mappings that will generalize these classes of mappings, thereby bridging the gap between these two classes of mappings?

In 2011, Falset et al. [11] introduced another class of mappings satisfying condition $\left(C_{\lambda}\right)$ and established some fixed point results for this class of mappings. Mappings satisfying $\left(C_{\lambda}\right)$ are proper generalization of mappings satisfying condition $(C)$.

Definition 1.3. Let $C$ be a nonempty subset of a Banach space $X$ and $\lambda \in(0,1)$. A mapping $T: C \rightarrow X$ is said to satisfy condition $\left(C_{\lambda}\right)$ on $C$ if for all $x, y \in C$,

$$
\lambda\|T x-x\| \leq\|x-y\| \Rightarrow\|T x-T y\| \leq\|x-y\| .
$$

Remark 1.4. It is easy to see that if $\lambda=\frac{1}{2}$, we obtain Suzuki generalized nonexpansive mapping. It is also worth mentioning that if we apply similar argument as in [29], we can obtain an example of a mapping that is mean nonexpansive but does not satisfying condition $\left(C_{\lambda}\right)$ and like-wise a mapping satisfying condition $\left(C_{\lambda}\right)$ that is not mean nonexpansive. Thus, we ask: Can we find a class of mappings that will generalize these classes of mappings?

Zhou and Cui in [45] studied the existence of fixed points for mean nonexpansive mappings and obtained the demiclosedness principle for this class of mappings in $\operatorname{CAT}(0)$ spaces. In addition, they proved a $\Delta$-convergence and strong convergence results of Ishikawa iteration process for mean nonexpansive mappings under some suitable conditions. For some recent generalizations of mean nonexpansive mappings, see ([9, 25] and the reference therein).

Several authors have introduced different iterative processes for approximating the fixed points of nonexpansive and other nonlinear mappings in Hilbert, Banach, Hadamard and $p$-uniformly convex metric spaces, see [4, 5, 16, 17, 21, 31, 32, 38, 39, 41. In general, developing a faster and more efficient iterative algorithms for approximating fixed points of nonlinear mappings is still an active area of research in nonlinear functional analysis and fixed point theory. The Mann iterative process [24] is one of the oldest and fundamental iterative process, which is given as follows:

$$
\left\{\begin{array}{l}
x_{0} \in C, \\
x_{n+1}=\left(1-\alpha_{n}\right) x_{n}+\alpha_{n} T x_{n}, \quad n \geq 0,
\end{array}\right.
$$

where $\left\{\alpha_{n}\right\}$ is a sequence in $(0,1)$ and $T$ is any nonlinear mapping on $C$.

In [19], Kadioglu and Yildirim introduced a Picard Normal S-iteration process and show that the rate of convergence of this iteration process is faster than that of Normal Siteration process. This iteration process is given as follows: For each $x_{0} \in C$, the 
sequence $\left\{x_{n}\right\}$ in $C$ is defined by

$$
\left\{\begin{array}{l}
z_{n}=\left(1-\beta_{n}\right) x_{n}+\beta_{n} T x_{n}, \\
y_{n}=\left(1-\alpha_{n}\right) z_{n}+\alpha_{n} T z_{n}, \\
x_{n+1}=T y_{n}, \quad n \geq 0
\end{array}\right.
$$

where $\left\{\alpha_{n}\right\}$ and $\left\{\beta_{n}\right\}$ are sequences in $(0,1)$ and $T$ is a nonlinear mapping on $C$.

In 2014, Gursoy and Karakay in [14] introduced the following iteration process called Picard-S iteration: For each $x_{0} \in C$, the sequence $\left\{x_{n}\right\}$ in $C$ is defined by

$$
\left\{\begin{array}{l}
z_{n}=\left(1-\alpha_{n}\right) x_{n}+\alpha_{n} T x_{n}, \\
y_{n}=\left(1-\beta_{n}\right) T x_{n}+\beta_{n} T z_{n}, \\
x_{n+1}=T y_{n}, \quad n \geq 0,
\end{array}\right.
$$

where $\left\{\alpha_{n}\right\}$ and $\left\{\beta_{n}\right\}$ are sequences in $(0,1)$ and $\mathrm{T}$ is a nonlinear mapping on $C$. They proved that this iterative process converges faster than the Mann [24], Ishikawa [15], Noor [30, Abbas et al. [1, and some other existing iterative schemes in literature. In 2017, Karakaya et al. in [20] introduced the following iteration process: For each $x_{0} \in C$, the sequence $\left\{x_{n}\right\}$ in $C$ is defined by

$$
\left\{\begin{array}{l}
z_{n}=T x_{n}, \\
y_{n}=\left(1-\alpha_{n}\right) z_{n}+\alpha_{n} T z_{n}, \\
x_{n+1}=T y_{n}, \quad n \geq 0
\end{array}\right.
$$

where $\left\{\alpha_{n}\right\}$ is a sequence in $(0,1)$. They proved that this iterative process converges faster than Mann [24, Ishikawa [15, Noor [30, Abass et al. [1] and some other existing iterative schemes in literature.

In 2018, Ullah et al. 42] introduced the following iteration process called the M-iteration process: For each $x_{0} \in C$, the sequence $\left\{x_{n}\right\}$ in $C$ is defined by

$$
\left\{\begin{array}{l}
z_{n}=\left(1-\alpha_{n}\right) x_{n}+\alpha_{n} T x_{n}, \\
y_{n}=T z_{n} \\
x_{n+1}=T y_{n}, \quad n \geq 0,
\end{array}\right.
$$

where $\left\{\alpha_{n}\right\}$ is a sequence in $(0,1)$. They proved that this iterative process converges faster than Mann [24], Ishikawa [15], Noor [30], Abass et al. [1], iterative process (1.4), iterative process (1.3) and some existing iterative schemes in literature. It was shown in (2) that the iterative process (1.5) and (1.6) have the same rate of convergence.

Remark 1.5. Since it is more desirable to construct iterative processes that are more efficient and have higher rate of convergence, we then ask: Can we construct a more efficient iterative process with better rate of convergence than the existing ones?

It is well-known that nonexpansive mappings are continuous on their domain and the continuity nature of this class of mappings make it less important in theoretical and application wise. On the other hand, it has been shown that mean nonexpansive mappings, Suzuki generalized nonexpansive mappings, mapping satisfying condition $\left(C_{\lambda}\right)$ need not be continuous on their domain. As such, these classes of mappings have great importance in theoretical and application-wise compare to nonexpansive mappings. Motivated by the research work described above and the current research interest in this direction, our purpose in this paper is to introduce a new class of generalized mean nonexpansive mappings and propose a new three steps iteration process for approximating the fixed point of this class of mappings in uniformly convex Banach spaces. Using this iteration process, we obtain some convergence results for approximating the fixed points of this 
class of mappings. Furthermore, we show that our proposed iterative scheme performs faster than some existing iterative schemes in the literature.

\section{Preliminaries}

Let $X$ be a Banach space with dimension greater than or equal to 2 . The function $\delta_{X}:(0,2] \rightarrow[0,1]$ defined by

$$
\delta_{X}(\epsilon)=\inf \left\{1-\left\|\frac{1}{2}(x+y)\right\|:\|x\|=1 ;\|y\|=1, \epsilon=\|x-y\|\right\}
$$

is called the modulus of convexity of $X$. If $\delta_{X}(\epsilon)>0$ for all $\epsilon \in(0,2]$, then $X$ is called uniformly convex. Let $X$ be a Banach space, $X^{*}$ its dual and $S(X)=\{x \in X:\|x\|=1\}$. The value of $f \in X^{*}$ at $x \in X$ is denoted by $\langle x, f\rangle$.

Definition 2.1. (1) The multivalued mapping $J: X \rightarrow 2^{X^{*}}$ defined by

$$
J(x)=\left\{f \in X^{*}:\langle x, f\rangle=\|x\|^{2}=\|f\|^{2}\right\}
$$

is called the normalized duality mapping.

(2) A Banach space $X$ is called smooth if $\lim _{t \rightarrow 0} \frac{\|x+t y\|-\|x\|}{t}$ exists for each $x, y \in$ $S(X)$. In this case, the norm of $X$ is called Gateaux differentiable. It is known that $J$ is single valued whenever $X$ is smooth.

(3) A Banach space $X$ is Frechet differentiable, if for each $x \in S(X)$, the limit above exists and is attained uniformly for $y \in S(X)$. In this case, we have that for all $x, h \in X$,

$$
\langle h, J(x)\rangle+\frac{1}{2}\|x\|^{2} \leq \frac{1}{2}\|x+h\|^{2} \leq\langle h, J(x)\rangle+\frac{1}{2}\|x\|^{2}+b(\|h\|),
$$

where $b$ is an increasing function defined on $[0, \infty)$ such that $\lim _{t \downarrow 0} \frac{b(t)}{t}=0$.

(4) A Banach space $X$ is said to have Opial property [33], if for every weakly convergent sequence $\left\{x_{n}\right\}$ in $X$ with weak limit $y$, we have

$$
\liminf _{n \rightarrow \infty}\left\|x_{n}-y\right\|<\liminf _{n \rightarrow \infty}\left\|x_{n}-z\right\| \forall z \in X,
$$

with $y \neq z$.

Let $C$ be a nonempty subset of a Banach space $X$ and $\left\{x_{n}\right\}$ a bounded sequence in $X$. For all $x, y \in X$, we define

(1) asymptotic radius of $\left\{x_{n}\right\}$ at $x$ by $r\left(x,\left\{x_{n}\right\}\right)=\lim _{\sup _{n \rightarrow \infty}}\left\|x_{n}-x\right\|$;

(2) asymptotic radius of $\left\{x_{n}\right\}$ relative to $C$ by $r\left(C,\left\{x_{n}\right\}\right)=\inf \left\{r,\left(x,\left\{x_{n}\right\}\right): x \in C\right\}$;

(3) asymptotic center of $\left\{x_{n}\right\}$ relative to $C$ by $A\left(C,\left\{x_{n}\right\}\right)=\left\{r\left(x,\left\{x_{n}\right\}\right)=r\left(C,\left\{x_{n}\right\}\right)\right.$ : $x \in C\}$.

We note that $A\left(C,\left\{x_{n}\right\}\right)$ is not empty and more so, if $X$ is uniformly convex, then $A\left(C,\left\{x_{n}\right\}\right)$ has exactly one point (see [12]).

In the sequel, we refer to $F(T)$ as the set of fixed points of $T$.

Definition 2.2. Let $C$ be a subset of a normed space $X$. A mapping $T: C \rightarrow C$ is said to satisfy condition $(I)$ if there exists a nondecreasing function $f:[0, \infty) \rightarrow[0, \infty)$ such that $f(0)=0$ and $f(t)>0 \forall t \in(0, \infty)$ and that $\|x-T x\| \geq f(d(x, F(T)))$ for all $x \in C$, where $d(x, F(T))$ denotes distance from $x$ to $F(T)$.

Definition 2.3. Let $C$ be a nonempty subset of a Banach space $X$ and $\left\{x_{n}\right\}$ be a sequence in $X$. Then $\left\{x_{n}\right\}$ is said to be Fejer monotone with respect to $C$, if for all $x \in C$ and $n \in N$, we have

$$
\left\|x_{n+1}-x\right\| \leq\left\|x_{n}-x\right\|
$$


Lemma 2.4. 36] Let $X$ be a uniformly convex Banach space and $0<p \leq t_{n} \leq q<1$ for all $n \in \mathbb{N}$. Let $\left\{x_{n}\right\}$ and $\left\{y_{n}\right\}$ be two sequences in $X$ such that $\lim _{\sup _{n \rightarrow \infty}}\left\|x_{n}\right\| \leq c$, $\limsup _{n \rightarrow \infty}\left\|y_{n}\right\| \leq c$ and $\lim _{n \rightarrow \infty}\left\|t_{n} x_{n}+\left(1-t_{n}\right) y_{n}\right\|=c$ holds for some $c \geq 0$. Then $\lim _{n \rightarrow \infty}\left\|x_{n}-y_{n}\right\|=0$.

\section{Generalized Mean Nonexpansive Mappings}

In this section, we introduce a class of mappings called the generalized mean nonexpansive mappings. We give some basic properties and demiclosedness principle for this class of mappings.

Definition 3.1. Let $C$ be a nonempty subset of a Banach space $X$. A mapping $T: C \rightarrow$ $X$ will be called generalized mean nonexpansive mapping if there exist $a, b, \lambda \in[0,1]$, with $a+b \leq 1$ such that for all $x, y \in C$,

$$
\lambda\|T x-x\| \leq\|x-y\| \Rightarrow\|T x-T y\| \leq a\|x-y\|+b\|x-T y\| .
$$

Remark 3.2. It is easy to see that

(1) nonexpansive mappings are generalized mean nonexpansive,

(2) mean nonexpansive mappings are generalized mean nonexpansive,

(3) mappings satisfying condition $(C)$ are generalized mean nonexpansive,

(4) mappings satisfying condition $\left(C_{\lambda}\right)$ are generalized mean nonexpansive.

The following example shows that the converse of these statements are not always true.

Example 3.3. Suppose $X=\mathbb{R}$ and $C=\{0,0.1,0.2, \cdots, 4\}$. Let $T: C \rightarrow \mathbb{R}$ be a mapping defined by

$$
T x=\left\{\begin{array}{lll}
\frac{3}{2} & \text { if } & x \in[0,3], \\
1 & \text { if } & x \in(3,4), \\
0 & \text { if } & x=4 .
\end{array}\right.
$$

Then $T$ is a generalized mean nonexpansive but does not satisfy condition $\left(C_{\lambda}\right)$ and consequently $T$ does not satisfy condition $(C)$ and not a nonexpansive mapping.

Proof. To show that $T$ is a generalized mean nonexpansive mapping, we take $\lambda=\frac{1}{30}$ and $a=b=\frac{1}{2}$ and consider the following cases:

Case 1: Suppose $x, y \in[0,3]$. For this case, we consider the following subcases.

Case 1(a): Suppose $x=y$.

$$
\lambda\|x-T x\|=\frac{1}{30}|x-1.5| \geq 0=\|x-y\| .
$$

If

$$
\lambda\|x-T x\|=\frac{1}{30}|x-1.5|=0=\|x-y\|,
$$

we have

$$
\|T x-T y\|=0 \leq \frac{1}{2}\|x-y\|+\frac{1}{2}\|x-T y\| .
$$

On the other hand, if

$$
\lambda\|x-T x\|=\frac{1}{30}|x-1.5|>0=\|x-y\| .
$$

Then, we have nothing to show.

Case 1(b): Suppose $x \neq y$.

$$
\lambda\|x-T x\|=\frac{1}{30}|x-1.5| \leq 0.1 \leq\|x-y\| .
$$


We then have that

$$
\|T x-T y\|=0 \leq \frac{1}{2}\|x-y\|+\frac{1}{2}\|x-T y\| .
$$

Case 2: Suppose $x \in[0,3]$ and $y \in(3,4)$.

$$
\lambda\|x-T x\|=\frac{1}{30}|x-1.5| \leq 0.1 \leq\|x-y\| .
$$

We then have that

$$
\begin{aligned}
\|T x-T y\|=\frac{1}{2} & \leq \frac{1}{2}\|y-T y\| \\
& =\frac{1}{2}\|y-x+x-T y\| \\
& \leq \frac{1}{2}\|x-y\|+\frac{1}{2}\|x-T y\| .
\end{aligned}
$$

Case 3: Suppose $x \in[0,3]$ and $y=4$.

$$
\lambda\|x-T x\|=\frac{1}{30}|x-1.5|<1 \leq\|x-y\| .
$$

We then have that

$$
\begin{aligned}
\|T x-T y\|=1.5 & \leq \frac{1}{2}\|y-T y\| \\
& =\frac{1}{2}\|y-x+x-T y\| \\
& \leq \frac{1}{2}\|x-y\|+\frac{1}{2}\|x-T y\| .
\end{aligned}
$$

Case 4: Suppose $x \in(3,4)$ and $y=[0,3]$.

$$
\lambda\|x-T x\|=\frac{1}{30}|x-1| \leq\|x-y\| .
$$

We then have that

$$
\begin{aligned}
\|T x-T y\|=\frac{1}{2} & \leq \frac{1}{2}\|2 x-(y+T y)\| \\
& =\frac{1}{2}\|x-y+x-T y\| \\
& \leq \frac{1}{2}\|x-y\|+\frac{1}{2}\|x-T y\| .
\end{aligned}
$$

Case 5: Suppose $x \in(3,4)$ and $y=4$.

$$
\lambda\|x-T x\|=\frac{1}{30}|x-1|<0.1 \leq\|x-y\| .
$$

We then have that

$$
\begin{aligned}
\|T x-T y\|=1 & =\frac{1}{2}\|2 x-(y+T y)\| \\
& =\frac{1}{2}\|x-y+x-T y\| \\
& \leq \frac{1}{2}\|x-y\|+\frac{1}{2}\|x-T y\| .
\end{aligned}
$$

Case 6: Suppose $x=4$ and $y \in[0,3]$.

$$
\lambda\|x-T x\|=\frac{1}{30}|4-0|<1 \leq\|x-y\| .
$$


We then have that

$$
\begin{aligned}
\|T x-T y\|=1.5 & \leq \frac{1}{2}\|2 x-(y+T y)\| \\
& =\frac{1}{2}\|x-y+x-T y\| \\
& \leq \frac{1}{2}\|x-y\|+\frac{1}{2}\|x-T y\| .
\end{aligned}
$$

Case 7: Suppose $x=4$ and $y \in(3,4)$.

$$
\lambda\|x-T x\|=\frac{1}{30}|4-0| \leq\|x-y\| .
$$

We then have that

$$
\begin{aligned}
\|T x-T y\|=1 & \leq \frac{1}{2}\|2 x-(y+T y)\| \\
& =\frac{1}{2}\|x-y+x-T y\| \\
& \leq \frac{1}{2}\|x-y\|+\frac{1}{2}\|x-T y\| .
\end{aligned}
$$

It is easy to see that the other cases follows similar approach. Hence, $T$ is a generalized mean nonexpansive mapping.

However, we now show that $T$ does not satisfy condition $C_{\lambda}$. For any $\lambda \in(0,1), x=2.7$ and $y=4$, we have that

$$
\lambda\|x-T x\|=\lambda(1.2)<1.2<1.3=\|x-y\|,
$$

but

$$
\|T x-T y\|=1.5>1.3=\|x-y\| .
$$

Hence, $T$ does not satisfy condition $C_{\lambda}$ and consequently $T$ does not satisfy condition $(C)$ and $T$ is not a nonexpansive mapping.

Proposition 3.1. Let $C$ be a nonempty subset of a Banach space $X$ and $T: C \rightarrow X$ be a generalized mean nonexpansive mapping with $F(T) \neq \emptyset$. Then $T$ is quasi-nonexapansive.

Proof. Let $x \in F(T)$ and $y \in C$,

$$
\lambda\|T x-x\|=0 \leq\|x-y\| .
$$

So, we have

$$
\begin{aligned}
\|x-T y\|=\|T x-T y\| & \leq a\|x-y\|+b\|x-T y\| \\
\Rightarrow(1-b)\|x-T y\| & \leq(1-b)\|x-y\| \\
\Rightarrow\|x-T y\| & \leq\|x-y\| .
\end{aligned}
$$

Hence, $T$ is quasi-nonexpanisve.

Theorem 3.4. Let $C$ be a nonempty subset of a Banach space $X$ and $T: C \rightarrow X$ be a generalized mean nonexpansive mapping. Then $F(T)$ is closed. Furthermore, if $X$ is strictly convex and $C$ is convex, then $F(T)$ is convex.

Proof. Let $\left\{x_{n}\right\}$ be a sequence in $F(T)$ such that $\left\{x_{n}\right\}$ converges to some $y \in C$. We show that $y \in F(T)$. Since

$$
\lambda\left\|T x_{n}-x_{n}\right\|=0 \leq\left\|x_{n}-y\right\|,
$$


so, we have

$$
\begin{aligned}
\left\|x_{n}-T y\right\| & =\left\|T x_{n}-T y\right\| \\
& \leq a\left\|x_{n}-y\right\|+b\left\|x_{n}-T y\right\| \\
\Rightarrow\left\|x_{n}-T y\right\| & \leq\left\|x_{n}-y\right\| .
\end{aligned}
$$

Since $\lim _{n \rightarrow \infty}\left\|x_{n}-y\right\|=0$, we obtain

$$
\lim _{n \rightarrow \infty}\left\|x_{n}-T y\right\|=0 .
$$

As such, we have that

$$
T y=y .
$$

Hence, $F(T)$ is closed.

Now suppose that $X$ is strictly convex and $C$ is convex. We show that $F(T)$ is convex. Let $\beta \in(0,1)$ and $x, y \in F(T)$ with $x \neq y$. Since

$$
\lambda\|x-T x\|=0 \leq\|x-z\|,
$$

we obtain

$$
\begin{gathered}
\|x-T z\|=\|T x-T z\| \leq a\|x-z\|+b\|x-T z\| \\
\Rightarrow\|x-T z\| \leq\|x-z\| .
\end{gathered}
$$

Using similar argument, we have

$$
\|y-T z\| \leq\|y-z\| .
$$

Let $z=\beta x+(1-\beta) y \in C$, for $\beta \in[0,1]$, then from (3.9) and (3.10), we obtain

$$
\begin{aligned}
\|x-y\| & \leq\|x-T z\|+\|T z-y\| \\
& \leq\|x-z\|+\|z-y\| \\
& =\|x-(\beta x+(1-\beta) y)\|+\|(\beta x+(1-\beta) y-y \| \\
& \leq(1-\beta)\|x-x\|+\beta\|x-y\|+(1-\beta)\|x-y\|+\beta\|y-y\| \\
& =\|x-y\| .
\end{aligned}
$$

Using the fact that $X$ is strictly convex, there exists $\mu \in[0,1]$ such that $T z=\mu x+(1-\mu) y$. Now

$$
(1-\mu)\|x-y\|=\|T x-T z\| \leq\|x-z\|=(1-\beta)\|x-y\|
$$

and

$$
\mu\|x-y\|=\|T y-T z\| \leq\|x-z\|=\beta\|x-y\| .
$$

From the above inequalities, we have that $1-\mu \leq 1-\beta$ and $\mu \leq \beta$, this implies that $\mu=\beta$. Thus, $z \in F(T)$, which implies that $F(T)$ is convex.

Lemma 3.5. Let $C$ be a nonempty subset of a Banach space $X$. Suppose that $T: C \rightarrow C$ is a generalized mean nonexpansive mapping on $C$. Then for all $x, y \in C$ and for $\beta \in[0,1]$, we have the following

(1) $\left\|T^{2} x-T x\right\| \leq\|T x-x\|$,

(2) either $\frac{\beta}{2}\|x-T x\| \leq\|x-y\|$ or $\frac{\beta}{2}\left\|T x-T^{2} x\right\| \leq\|T x-y\|$,

(3) either $\|T x-T y\| \leq a\|x-y\|+b\|x-T y\|$ or $\left\|T^{2} x-T y\right\| \leq a\|T x-y\|+b\|T x-T y\|$.

Proof. (1) For $x \in C$, we have that $\lambda\|T x-x\| \leq\|T x-x\|$, which implies that

$$
\left\|T^{2} x-T x\right\|=\|T(T x)-T x\| \leq a\|T x-x\|+b\|T x-T x\| \leq\|T x-x\| .
$$


(2) Suppose on the contrary that $\frac{\beta}{2}\|x-T x\|>\|x-y\|$ or $\frac{\beta}{2}\left\|T x-T^{2} x\right\|>\|T x-y\|$ for some $x, y \in C$. Now, using (1), observe that

$$
\begin{aligned}
\|x-T x\| & \leq\|x-y\|+\|y-T x\| \\
& <\frac{\beta}{2}\|x-T x\|+\frac{\beta}{2}\left\|T x-T^{2} x\right\| \\
& \leq \frac{\beta}{2}\|x-T x\|+\frac{\beta}{2}\|x-T x\| \\
& =\beta\|x-T x\| \\
& \leq\|x-T x\|,
\end{aligned}
$$

which is a contradiction. Thus, we obtain the desired result.

(3) The proof of (3) follows from (2). Thus we omit it.

Lemma 3.6. Let $C$ be a nonempty subset of a Banach spce $X$ and $T: C \rightarrow C$ a generalized mean nonexpansvie mapping. Then for all $x, y \in C$,

$$
\|x-T y\| \leq \frac{(2+a+b)}{(1-b)}\|x-T x\|+\|x-y\| .
$$

Proof. From Lemma 3.5, we have for $x, y \in C$ that $\|T x-T y\| \leq a\|x-y\|+b\|x-T y\|$ or $\left\|T^{2} x-T y\right\| \leq a\|T x-y\|+b\|T x-T y\|$.

Considering $\|T x-T y\| \leq a\|x-y\|+b\|x-T y\|$, we obtain that

$$
\begin{aligned}
\|x-T y\| & \leq\|x-T x\|+\|T x-T y\| \\
& \leq\|x-T x\|+a\|x-y\|+b\|x-T y\| \\
& \leq\|x-T x\|+(1-b)\|x-y\|+b\|x-T y\| \\
\Rightarrow & \|x-T y\| \leq \frac{1}{(1-b)}\|x-T x\|+\|x-y\| \leq \frac{(2+a+b)}{(1-b)}\|x-T x\|+\|x-y\| .
\end{aligned}
$$

Also, considering $\left\|T^{2} x-T y\right\| \leq a\|T x-y\|+b\|T x-T y\|$, using (1) of Lemma 3.5, we obtain that

$$
\begin{aligned}
\|x-T y\| & \leq\|x-T x\|+\left\|T x-T^{2} x\right\|+\left\|T^{2} x-T y\right\| \\
& \leq\|x-T x\|+\|x-T x\|+a\|T x-y\|+b\|T x-T y\| \\
& \leq 2\|x-T x\|+a\|T x-x\|+a\|x-y\|+b\|T x-x\|+b\|x-T y\| \\
& \leq(2+a+b)\|x-T x\|+(1-b)\|x-y\|+b\|x-T y\| \\
\Rightarrow & \|x-T y\| \leq \frac{(2+a+b)}{(1-b)}\|x-T x\|+\|x-y\| .
\end{aligned}
$$

Thus in both cases, we obtain the desired result.

Theorem 3.7. Let $C$ be a nonempty closed subset of a Banach space $X$ with Opial property and $T: C \rightarrow C$ be a generalized mean nonexpansive mapping with $\lambda=\frac{\beta}{2}, \beta \in$ $[0,1]$. If $\left\{x_{n}\right\}$ converges weakly to $x$ and $\lim _{n \rightarrow \infty}\left\|T x_{n}-x_{n}\right\|=0$, then $T x=x$. That is $I-T$ is demiclosed at zero, where $I$ is the identity mapping on $X$.

Proof. By Lemma 3.5

$$
\lambda\left\|x_{n}-T x_{n}\right\| \leq\left\|x_{n}-x\right\| .
$$

Thus by definition

$$
\left\|T x_{n}-T x\right\| \leq a\left\|x_{n}-x\right\|+b\left\|x_{n}-T x\right\| .
$$


Now, observe that

$$
\begin{aligned}
\left\|x_{n}-T x\right\| & \leq\left\|x_{n}-T x_{n}\right\|+\left\|T x_{n}-T x\right\| \\
& \leq\left\|x_{n}-T x_{n}\right\|+a\left\|x_{n}-x\right\|+b\left\|x_{n}-T x\right\| \\
& \leq\left\|x_{n}-T x_{n}\right\|+(1-b)\left\|x_{n}-x\right\|+b\left\|x_{n}-T x\right\| \\
\Rightarrow & \left\|x_{n}-T x\right\| \leq \frac{1}{(1-b)}\left\|x_{n}-T x_{n}\right\|+\left\|x_{n}-x\right\| .
\end{aligned}
$$

Using our hypothesis, we have that

$$
\liminf _{n \rightarrow \infty}\left\|x_{n}-T x\right\| \leq \liminf _{n \rightarrow \infty}\left\|x_{n}-x\right\| .
$$

Using our hypothesis that $\left\{x_{n}\right\}$ converges weakly to $x$ and Opial property, we have

$$
\liminf _{n \rightarrow \infty}\left\|x_{n}-x\right\| \leq \liminf _{n \rightarrow \infty}\left\|x_{n}-T x\right\|,
$$

which contradicts (3.14). Thus, we have that $T x=x$.

Theorem 3.8. Let $C$ be a nonempty closed convex subset of a uniformly convex Banach space $X$. Suppose that $T: C \rightarrow C$ is a generalized mean nonexpansive mapping on $C$ such that $\lambda=\frac{\beta}{2}$ with $\beta \in(0,1)$. Then $F(T) \neq \emptyset$ if and only if $\left\{T^{n}(x)\right\}$ is a bounded sequence for some $x \in C$, where $n \in \mathbb{N}$.

Proof. Suppose that $\left\{T^{n}(x)\right\}$ is a bounded sequence for some $x \in C$ and define $\left\{x_{n}\right\}=$ $\left\{T^{n}(x)\right\}$ for all $n \in \mathbb{N}$. Then there exists $y \in C$ such that $A\left(C,\left\{x_{n}\right\}\right)=\{y\}$. Since

$$
\frac{\beta}{2}\left\|T x_{n}-x_{n}\right\|=\frac{\beta}{2}\left\|x_{n+1}-x_{n}\right\| \leq\left\|x_{n+1}-x_{n}\right\|,
$$

we obtain that

$$
\begin{aligned}
\left\|x_{n+2}-x_{n+1}\right\| & =\left\|T x_{n+1}-T x_{n}\right\| \\
& \leq a\left\|x_{n+1}-x_{n}\right\|+b\left\|x_{n+1}-T x_{n}\right\| \\
& =a\left\|x_{n+1}-x_{n}\right\|+b\left\|x_{n+1}-x_{n+1}\right\| \\
& \leq\left\|x_{n+1}-x_{n}\right\| .
\end{aligned}
$$

We claim that $\left\|x_{n+1}-x_{n}\right\| \leq \frac{2}{\beta}\left\|x_{n}-y\right\|$ or $\left\|x_{n+2}-x_{n+1}\right\| \leq \frac{2}{\beta}\left\|x_{n+1}-y\right\|$ for all $n \in \mathbb{N}$. Suppose on the contrary that $\frac{2}{\beta}\left\|x_{n}-y\right\|<\left\|x_{n+1}-x_{n}\right\|$ or $\frac{2}{\beta}\left\|x_{n+1}-y\right\|<\left\|x_{n+2}-x_{n+1}\right\|$. Now, observe that

$$
\begin{aligned}
\left\|x_{n+1}-x_{n}\right\| & \leq\left\|x_{n+1}-y\right\|+\left\|y-x_{n}\right\| \\
& <\frac{\beta}{2}\left\|x_{n+2}-x_{n+1}\right\|+\frac{\beta}{2}\left\|x_{n+1}-x_{n}\right\| \\
& \leq \frac{\beta}{2}\left\|x_{n+1}-x_{n}\right\|+\frac{\beta}{2}\left\|x_{n+1}-x_{n}\right\| \\
& =\beta\left\|x_{n+1}-x_{n}\right\| \\
& \leq\left\|x_{n+1}-x_{n}\right\| .
\end{aligned}
$$

Thus we have a contradiction. Hence for all $n \in \mathbb{N}$, we have that $\left\|x_{n+1}-x_{n}\right\| \leq \frac{2}{\beta}\left\|x_{n}-y\right\|$ or $\left\|x_{n+2}-x_{n+1}\right\| \leq \frac{2}{\beta}\left\|x_{n+1}-y\right\|$.

Now, considering the first case, $\frac{\beta}{2}\left\|x_{n+1}-x_{n}\right\|=\frac{\beta}{2}\left\|T x_{n}-x_{n}\right\| \leq\left\|x_{n}-y\right\|$. By definition, 
we have that

$$
\begin{aligned}
\left\|T x_{n}-T y\right\| & \leq a\left\|x_{n}-y\right\|+b\left\|x_{n}-T y\right\| \\
& \leq(1-b)\left\|x_{n}-y\right\|+b\left\|x_{n}-T y\right\| \\
\Rightarrow & \limsup _{n \rightarrow \infty}\left\|T x_{n}-T y\right\| \leq a \limsup _{n \rightarrow \infty}\left\|x_{n}-y\right\|+b \limsup _{n \rightarrow \infty}\left\|x_{n}-T y\right\| \\
\Rightarrow & \limsup _{n \rightarrow \infty}\left\|x_{n}-T y\right\| \leq \limsup _{n \rightarrow \infty}\left\|x_{n}-y\right\| .
\end{aligned}
$$

Thus, we have $T(y) \in A\left(C,\left\{x_{n}\right\}\right)$, so that $T y=y$. Using similar approach, we also obtain $T y=y$ for the second case. Thus $F(T) \neq \emptyset$.

Conversely, suppose $F(T) \neq \emptyset$. Then there exists say $y \in F(T)$ and by induction, we have that $T^{n} y=y$ for all $n \in \mathbb{N}$. Thus $\left\{T^{n}(y)\right\}$ is a constant sequence and so bounded.

\section{Convergence Results}

In this section, we propose a three steps iterative algorithm for approximating the fixed point of generalized mean nonexpansive mapping and establish the strong convergence of the algorithm. The propose iterative algorithm is given as follows: For each $x_{0} \in C$, the sequence $\left\{x_{n}\right\}$ in $C$ is defined by

$$
\left\{\begin{array}{l}
z_{n}=\left(1-\gamma_{n}\right) x_{n}+\gamma_{n} T x_{n}, \\
y_{n}=T\left[\left(1-\alpha_{n}\right) z_{n}+\alpha_{n} T z_{n}\right], \\
x_{n+1}=T\left[\left(1-\beta_{n}\right) T z_{n}+\beta_{n} T y_{n}\right], \quad n \geq 0,
\end{array}\right.
$$

where $\left\{\alpha_{n}\right\},\left\{\beta_{n}\right\}$ and $\left\{\gamma_{n}\right\}$ are sequences in $[0,1]$.

Lemma 4.1. Let $C$ be a nonempty closed and convex subset of a uniformly convex Banach space $X$ and $T: C \rightarrow C$ be a generalized mean nonexpansive mapping with $F(T) \neq \emptyset$. Suppose that $\left\{x_{n}\right\}$ is defined by 4.15), where $\left\{\beta_{n}\right\},\left\{\gamma_{n}\right\}$ and $\left\{\alpha_{n}\right\}$ are sequences in $[0,1]$. Then the following hold:

(i) $\left\{x_{n}\right\}$ is bounded.

(ii) $\lim _{n \rightarrow \infty}\left\|x_{n}-x^{*}\right\|$ exists for all $x^{*} \in F(T)$.

Proof. Using (4.15) and Proposition 3.1, we have

$$
\begin{aligned}
\left\|z_{n}-x^{*}\right\| & \leq\left(1-\gamma_{n}\right)\left\|x_{n}-x^{*}\right\|+\gamma_{n}\left\|T x_{n}-x^{*}\right\| \\
& \leq\left(1-\gamma_{n}\right)\left\|x_{n}-x^{*}\right\|+\gamma_{n}\left\|x_{n}-x^{*}\right\| \\
& \leq\left\|x_{n}-x^{*}\right\| .
\end{aligned}
$$

Using (4.15), (4.16) and Proposition 3.1, we have

$$
\begin{aligned}
\left\|y_{n}-x^{*}\right\| & =\left\|T\left[\left(1-\alpha_{n}\right) z_{n}+\alpha_{n} T z_{n}\right]-x^{*}\right\| \\
& \leq\left(1-\alpha_{n}\right)\left\|z_{n}-x^{*}\right\|+\alpha_{n}\left\|T z_{n}-x^{*}\right\| \\
& \leq\left(1-\alpha_{n}\right)\left\|z_{n}-x^{*}\right\|+\alpha_{n}\left\|z_{n}-x^{*}\right\| \\
& =\left\|z_{n}-x^{*}\right\| \\
& =\left\|x_{n}-x^{*}\right\| .
\end{aligned}
$$

Using (4.15), (4.17) and Proposition 3.1, we have

$$
\begin{aligned}
\left\|x_{n+1}-x^{*}\right\| & =\left\|T\left[\left(1-\beta_{n}\right) T z_{n}+\beta_{n} T y_{n}\right]-x^{*}\right\| \\
& \leq\left(1-\beta_{n}\right)\left\|T z_{n}-x^{*}\right\|+\beta_{n}\left\|T y_{n}-x^{*}\right\| \\
& \leq\left(1-\beta_{n}\right)\left\|z_{n}-x^{*}\right\|+\beta_{n}\left\|y_{n}-x^{*}\right\| \\
& \leq\left(1-\beta_{n}\right)\left\|x_{n}-x^{*}\right\|+\beta_{n}\left\|x_{n}-x^{*}\right\| \\
& =\left\|x_{n}-x^{*}\right\| .
\end{aligned}
$$


This shows that $\left\{\left\|x_{n}-x^{*}\right\|\right\}$ is bounded and non-decreasing for all $x^{*} \in F(T)$. Thus $\left\{x_{n}\right\}$ is bounded and $\lim _{n \rightarrow \infty}\left\|x_{n}-x^{*}\right\|$ exists.

Lemma 4.2. Let $C$ be a nonempty closed and convex subset of a uniformly convex Banach space $X$ and $T: C \rightarrow C$ be a generalized mean nonexpansive mapping with $F(T) \neq \emptyset$. Suppose that $\left\{x_{n}\right\}$ is defined by 4.15), where $\left\{\beta_{n}\right\},\left\{\gamma_{n}\right\}$ and $\left\{\alpha_{n}\right\}$ are sequences in $[0,1]$, then $\lim _{n \rightarrow \infty}\left\|T x_{n}-x_{n}\right\|=0$.

Proof. Since $F(T) \neq \emptyset$, let $x^{*} \in F(T)$. We have established in Lemma 4.1 that $\left\{x_{n}\right\}$ is bounded and $\lim _{n \rightarrow \infty}\left\|x_{n}-x^{*}\right\|$ exists for all $x^{*} \in F(T)$. Suppose that $\lim _{n \rightarrow \infty} \| x_{n}-$ $x^{*} \|=c$. If we take $c=0$, then we are done. Thus, we consider the case where $c>0$.

From (4.16), we have $\left\|z_{n}-x^{*}\right\| \leq\left\|x_{n}-x^{*}\right\|$, it then follows that

$$
\limsup _{n \rightarrow \infty}\left\|z_{n}-x^{*}\right\| \leq c .
$$

Also, using Proposition 3.1, we have $\left\|T x_{n}-x^{*}\right\| \leq\left\|x_{n}-x^{*}\right\|$, it then follows that

$$
\limsup _{n \rightarrow \infty}\left\|T x_{n}-x^{*}\right\| \leq c
$$

Using (4.17) and (4.18), we have

$$
\begin{aligned}
\left\|x_{n+1}-x^{*}\right\| & =\left\|T\left[\left(1-\beta_{n}\right) T z_{n}+\beta_{n} T y_{n}\right]-x^{*}\right\| \\
& \leq\left(1-\beta_{n}\right)\left\|z_{n}-x^{*}\right\|+\beta_{n}\left\|y_{n}-x^{*}\right\| \\
& \leq\left(1-\beta_{n}\right)\left\|z_{n}-x^{*}\right\|+\beta_{n}\left\|x_{n}-x^{*}\right\| .
\end{aligned}
$$

Taking the $\liminf \operatorname{in}_{n \rightarrow \infty}$ of both sides and rearranging the inequalities, we have

$$
c \leq \liminf _{n \rightarrow \infty}\left\|z_{n}-x^{*}\right\| .
$$

From (4.19) and (4.21), we obtain that $\lim _{n \rightarrow \infty}\left\|z_{n}-x^{*}\right\|=c$. That is,

$$
\lim _{n \rightarrow \infty}\left\|\left(1-\gamma_{n}\right) x_{n}+\gamma_{n} T x_{n}-x^{*}\right\|=c .
$$

Thus by Lemma 2.4, we have

$$
\lim _{n \rightarrow \infty}\left\|x_{n}-T x_{n}\right\|=0
$$

Theorem 4.3. Let $X$ be a uniformly convex Banach space which satisfies the Opial's condition and $C$ a nonempty closed convex subset of $X$. Let $T: C \rightarrow C$ be a generalized mean nonexpansive mapping such that $\lambda=\frac{\beta}{2} \in\left[0, \frac{1}{2}\right]$ with $F(T) \neq \emptyset$ and $\left\{x_{n}\right\}$ be a sequence defined by Iteration 4.15). Then $\left\{x_{n}\right\}$ converges weakly to a fixed point of $T$.

Proof. In Lemma 4.1, we show that $\lim _{n \rightarrow \infty}\left\|x_{n}-x^{*}\right\|$ exists and that $\left\{x_{n}\right\}$ is bounded. Now, since $X$ is uniformly convex, we can find a subsequence say $\left\{x_{n_{i}}\right\}$ of $\left\{x_{n}\right\}$ that converges weakly in $C$. We now show that $\left\{x_{n}\right\}$ has a unique weak subsequential limit in $F(T)$. Let $u$ and $v$ be weak limits of the subsequences $\left\{x_{n_{k}}\right\}$ and $\left\{x_{n_{j}}\right\}$ of $\left\{x_{n}\right\}$ respectively. By Theorem 4.2, we have that $\lim _{n \rightarrow \infty}\left\|x_{n}-T x_{n}\right\|=0$ and $I-T$ is demiclosed with respect to zero by Theorem 3.7, we therefore have that $T u=u$. Using similar approach, we can show that $v=T v$. In what follows, we show uniqueness. From Lemma 4.1, we have that $\lim _{n \rightarrow \infty}\left\|x_{n}-v\right\|$ exists. Now, suppose that $u \neq v$, then by 
Opial's condition,

$$
\begin{aligned}
\lim _{n \rightarrow \infty}\left\|x_{n}-u\right\| & =\lim _{k \rightarrow \infty}\left\|x_{n_{k}}-u\right\| \\
& <\lim _{k \rightarrow \infty}\left\|x_{n_{k}}-v\right\| \\
& =\lim _{n \rightarrow \infty}\left\|x_{n}-v\right\| \\
& =\lim _{j \rightarrow \infty}\left\|x_{n_{j}}-v\right\| \\
& <\lim _{j \rightarrow \infty}\left\|x_{n_{j}}-u\right\| \\
& =\lim _{n \rightarrow \infty}\left\|x_{n}-u\right\| .
\end{aligned}
$$

This is a contradiction, so $u=v$. Hence $\left\{x_{n}\right\}$ converges weakly to a fixed point of $F(T)$ and this completes the proof.

Theorem 4.4. Let $C$ be a nonempty closed convex subset of a uniformly convex Banach space $X$. Let $T: C \rightarrow C$ be a generalized mean nonexpansive mapping on $C,\left\{x_{n}\right\}$ defined by 4.15$)$ and $F(T) \neq \emptyset$. Then $\left\{x_{n}\right\}$ converges strongly to a point of $F(T)$ if and only if $\liminf _{n \rightarrow \infty} d\left(x_{n}, F(T)\right)=0$ where $d(x, F(T))=\inf \left\{\left\|x-x^{*}\right\|: x^{*} \in F(T)\right\}$.

Proof. Suppose that $\left\{x_{n}\right\}$ converges to a fixed point, say $x^{*}$ of $T$. Then $\lim _{n \rightarrow \infty} d\left(x_{n}, x^{*}\right)=$ 0 , and since $0 \leq d\left(x_{n}, F(T)\right) \leq d\left(x_{n}, x^{*}\right)$, it follows that $\lim _{n \rightarrow \infty} d\left(x_{n}, F(T)\right)=0$. Therefore, $\liminf _{n \rightarrow \infty} d\left(x_{n}, F(T)\right)=0$.

Conversely, suppose that $\liminf _{n \rightarrow \infty} d\left(x_{n}, F(T)\right)=0$. From Lemma 4.1, we have that $\lim _{n \rightarrow \infty}\left\|x_{n}-x^{*}\right\|$ exists and that $\lim _{n \rightarrow \infty} d\left(x_{n}, F(T)\right)$ exists for all $x^{*} \in F(T)$. By our hypothesis, $\liminf _{n \rightarrow \infty} d\left(x_{n}, F(T)\right)=0$, so for any give $\epsilon>0$, there exists $n_{0} \in \mathbb{N}$, such that for all $n \geq n_{0}$, we have $d\left(x_{n}, F(T)\right) \leq \epsilon$. We now show that $\left\{x_{n}\right\}$ is a Cauchy sequence in $C$. Since, $\lim _{n \rightarrow \infty} d\left(x_{n}, F(T)\right)=0$, for any give $\epsilon>0$, there exists $n_{0} \in \mathbb{N}$ such that for $n, m \geq n_{0}$, we have

$$
\begin{aligned}
d\left(x_{m}, F(T)\right) & \leq \frac{\epsilon}{2}, \\
d\left(x_{n}, F(T)\right) & \leq \frac{\epsilon}{2} .
\end{aligned}
$$

Therefore, we have

$$
\begin{aligned}
\left\|x_{m}-x_{n}\right\| & \leq\left\|x_{m}-x^{*}\right\|+\left\|x_{n}-x^{*}\right\| \\
& \leq d\left(x_{m}, F(T)\right)+d\left(x_{n}, F(T)\right) \\
& \leq \frac{\epsilon}{2}+\frac{\epsilon}{2}=\epsilon .
\end{aligned}
$$

Hence $\left\{x_{n}\right\}$ is Cauchy in $C$. Since $C$ is closed, then there exists a point $x_{1} \in C$ such that $\lim _{n \rightarrow \infty} x_{n}=x_{1}$. Since $\lim _{n \rightarrow \infty} d\left(x_{n}, F(T)\right)=0$, it follows that $\lim _{n \rightarrow \infty} d\left(x_{1}, F(T)\right)=0$. Thus $x_{1} \in F(T)$ Since $F(T)$ is closed.

Theorem 4.5. Let $C$ be a nonempty closed convex subset of a uniformly convex Banach space $X$. Let $T: C \rightarrow C$ be a generalized mean nonexpansive mapping, $\left\{x_{n}\right\}$ defined by (4.15) and $F(T) \neq \emptyset$. Let $T$ satisfy condition $(I)$, then $\left\{x_{n}\right\}$ converges strongly to a fixed point of $T$.

Proof. From Lemma 4.1, we have $\lim _{n \rightarrow \infty}\left\|x_{n}-F(T)\right\|$ exists and by Theorem 4.2, we have $\lim _{n \rightarrow \infty}\left\|x_{n}-T x_{n}\right\|=0$. Using the fact that

$$
0 \leq \lim _{n \rightarrow \infty} f\left(d(x, F(T)) \leq \lim _{n \rightarrow \infty}\left\|x_{n}-T x_{n}\right\|=0 \forall x \in C,\right.
$$

we have that $\lim _{n \rightarrow \infty} f\left(d\left(x_{n}, F(T)\right)\right)=0$. Since $f$ is nondecreasing with $f(0)=0$ and $f(t)>0$ for $t \in(0, \infty)$, it then follows that $\lim _{n \rightarrow \infty} d\left(x_{n}, F(T)\right)=0$. Hence, by Theorem $4.4\left\{x_{n}\right\}$ converges strongly to $x^{*} \in F(T)$. 


\section{Numerical EXAMPles}

Example 5.1. Define a mapping $T:[0,1] \rightarrow[0,1]$ as

$$
T x=\left\{\begin{array}{l}
1-x \text { if } x \in[0,1 / 5), \\
\frac{x+4}{5} \text { if } x \in[1 / 5,1]
\end{array}\right.
$$

Then $T$ is a generalized mean nonexpansive mapping but not mean nonexpansive.

Proof. Suppose $T$ is mean nonexpansive, then there exist nonnegative real numbers $a$ and $b$, such that $a+b \leq 1$ and $\|T x-T y\| \leq a\|x-y\|+b\|x-T y\|$ for all $x, y \in[0,1]$. Now suppose $x=1$ and $y=0$, we then have that

$$
\begin{aligned}
\|T x-T y\| & =0 \\
& \leq a\|x-y\|+b\|x-T y\| \\
& =a .
\end{aligned}
$$

So $a \leq 1$ and $b=0$. Thus $T$ is nonexpansive, but this contradicts the fact that $T$ is not continuous. Hence $T$ is not mean nonexpansive.

To show that $T$ is generalized mean nonexpansive, it suffices to show that $T$ is Suzuki generalized nonexpansive. To do this, we consider the following cases:

Case 1: Let $x \in\left[0, \frac{1}{5}\right)$, as such, we have that $\frac{1}{2}\|x-T x\|=\frac{1-2 x}{2} \in\left(\frac{3}{10}, \frac{1}{2}\right]$. By definition, for $\frac{1}{2}\|x-T x\| \leq\|x-y\|$, we must have that $y \geq \frac{1}{2}$, that is $y \in\left[\frac{1}{2}, 1\right]$. And so, we have

$$
\|T x-T y\|=\left|\frac{5 x+y-1}{5}\right|<\frac{1}{5}
$$

and

$$
\|x-y\|=|x-y|>\left|\frac{1}{5}-\frac{1}{2}\right|=\frac{3}{10} .
$$

Thus we have that $\frac{1}{2}\|x-T x\| \leq\|x-y\| \Rightarrow\|T x-T y\| \leq\|x-y\|$.

Case 2: Let $x \in\left[\frac{1}{5}, 1\right]$, as such, we have that $\frac{1}{2}\|x-T x\|=\frac{2-2 x}{5} \in\left[0, \frac{4}{5}\right]$. By definition, for $\frac{1}{2}\|x-T x\| \leq\|x-y\|$, we must have that $\frac{2-2 x}{5} \leq|x-y|$. We have two possibilities.

Case 2a: If $x<y$, we have that $\frac{2-2 x}{5}<y-x$, as such we must have that $\frac{2+3 x}{5} \leq y \Rightarrow$ $y \in\left[\frac{13}{25}, 1\right] \subset\left[\frac{1}{5}, 1\right]$. And so, we obtain that

$$
\|T x-T y\|=\left|\frac{x+4}{5}-\frac{y+4}{5}\right|=\frac{1}{5}|x-y| \leq\|x-y\| .
$$

Thus we have that $\frac{1}{2}\|x-T x\| \leq\|x-y\| \Rightarrow\|T x-T y\| \leq\|x-y\|$.

Case 2b: If $x \geq y$, we have that $\frac{2-2 x}{5} \leq x-y$, as such, we have $y \leq \frac{7 x-2}{5} \Rightarrow y \in\left[\frac{-3}{25}, 1\right]$. We only need to consider the case in which $y \in[0,1]$. For $y \leq \frac{7 x-2}{5}$, we obtain that $x \geq \frac{5 y+2}{7}$, which implies that $x \in\left[\frac{2}{7}, 1\right]$, as such we consider $x \in\left[\frac{2}{7}, 1\right]$ and $y \in[0,1]$. For $x \in\left[\frac{2}{7}, 1\right]$ and $y \in\left[\frac{1}{5}, 1\right]$ have been considered in case 2 a. So, we consider $x \in\left[\frac{2}{7}, 1\right]$ and $y \in\left[0, \frac{1}{5}\right)$. To start with, suppose $x \in\left[\frac{2}{7}, \frac{2}{5}\right]$ and $y \in\left[0, \frac{1}{5}\right)$, we therefore have that

$$
\|T x-T y\|=\left|\frac{x+4}{5}-(1-y)\right|=\left|\frac{x+5 y-1}{5}\right| \leq \frac{2}{25}
$$

and

$$
\|x-y\|=|x-y|>\left|\frac{2}{7}-\frac{1}{5}\right|=\frac{3}{35} .
$$


Thus we have that $\frac{1}{2}\|x-T x\| \leq\|x-y\| \Rightarrow\|T x-T y\| \leq\|x-y\|$.

Also for $x \in\left[\frac{2}{5}, 1\right]$ and $y \in\left[0, \frac{1}{5}\right)$, we therefore have that

$$
\|T x-T y\|=\left|\frac{x+4}{5}-(1-y)\right|=\left|\frac{x+5 y-1}{5}\right| \leq \frac{1}{5}
$$

and

$$
\|x-y\|=|x-y|>\left|\frac{2}{5}-\frac{1}{5}\right|=\frac{1}{5} .
$$

Thus we have that $\frac{1}{2}\|x-T x\| \leq\|x-y\| \Rightarrow\|T x-T y\| \leq\|x-y\|$. Hence $T$ is Suzuki generalized nonexpansive and so a generalized mean nonexpansive.

In what follows, we numerically compare our new iteration process with some existing iterative processes. Taking $\alpha_{n}=\frac{2 n}{\sqrt{7 n+9}}, \gamma_{n}=\frac{2}{\sqrt{n+9}}, \beta_{n}=\frac{1}{3 n+7}$ and $x_{0}=0.9$.

\begin{tabular}{|c|c|c|c|c|}
\hline Step & Our Algorithm & Karakay et al. Algorithm & M. Algorithm & Picard-S Algorithm \\
\hline$x_{0}$ & 0.9 & 0.9 & 0.9 & 0.9 \\
\hline$x_{1}$ & 0.9967649 & 0.9960000 & 0.9960000 & 0.9960000 \\
\hline$x_{2}$ & 0.9999356 & 0.9999040 & 0.9999040 & 0.9998602 \\
\hline$x_{3}$ & 1 & 0.9999987 & 0.9999987 & 0.9999954 \\
\hline$x_{4}$ & 1 & 1 & 1 & 0.9999999 \\
\hline$x_{5}$ & 1 & 1 & 1 & 1 \\
\hline
\end{tabular}

This comparison shows that the iterative processes (4.15) converges faster than the iterative processes (1.4), (1.5) and (1.6). More so, the iterative processes (1.5) and (1.6) converges at the same time.

\section{Conclusion}

In this paper, we introduced a class of mappings, called the generalized mean nonexpansive mappings and obtained some fixed point results for this class of mappings. In addition, we proposed an iterative algorithm for approximating the fixed point of this class of mappings and established the convergence of the iterative algorithm in uniformly convex Banach spaces. Furthermore, we show that the proposed iterative process is more efficient and converges faster than some iterative processes in literature.

Conflict of Interest: The authors declare that there is no conflict of interests.

\section{REFERENCES}

[1] M. Abass and T. Nazir, A new faster iteration process applied to constrained minimization and feasibility problems, Mat. Vesnik, 66 (2), (2014), 223-234.

[2] H.A. Abass, A.A. Mebawondu and O.T. Mewomo, Some results for a new three steps iteration scheme in Banach spaces, Bull. Transilv. Univ. Brasov Ser. III 11 (60) No. 2, (2018), 1-18.

[3] C. T. Aage and J. N .Salunke, Fixed points for weak contractions in G-metric spaces, Appl. Math. E-Notes., 12, (2012), 23-28.

[4] K.O. Aremu, C. Izuchukwu, G.N. Ogwo, O.T. Mewomo, Multi-step Iterative algorithm for minimization and fixed point problems in p-uniformly convex metric spaces, J. Ind. Manag. Optim., (2020), doi:10.3934/jimo.2020063.

[5] K.O. Aremu, L.O Jolaoso, C. Izuchukwu, O.T. Mewomo, Approximation of common solution of finite family of monotone inclusion and fixed point problems for demicontractive multivalued mappings in CAT(0) spaces, Ric. Mat. 69 (1), (2020), 13-34.

[6] S. Banach, Sur les oprations dans les ensembles abstraits et leur application aux quations intgrales, Fundamenta Mathematicae, 3, (1922), 133-181.

[7] M. Basarir and A. Sahir, On the strong and $\Delta$-convergence of New multi-step and S-iteration process in $C A T(0)$ space, J. Inequal. Appl., 2013, (2013), Art ID 311, 10 pp.

[8] F. E. Browder, Nonexpansive nonlinear operators in a Banach space, Proc. Nat. Acad. Sci. U.S.A. 54 (1965), 1041-1044. 
[9] L. Chen, L. Guo and D. Chen, Fixed point theorems of mean nonexpansive set-valued mappings in Banach spaces, J. Fixed Point Theory Appl. 19 (2017), 2129-2143.

[10] B. S. Choudhury and C. Bandyopadhyay, Suzuki type common fixed point theorem in complete metric space and partial metric space, Filomat., 29 (6), (2015) 1377-1387.

[11] J. G. Falset, E. L. Fuster and T. Suzuki Fixed point theory for a class of generalizec nonexpansive mappings, J. Math. Anal. Appl. 375 (2011), 185-195.

[12] K. Goebel and W. A. Kirk, Topics in metric fixed point theory, Cambridge University Press.

[13] D. Gohde, Zum prinzip de kontraktive abbilding, Math. Nachr. 30 251-258.

[14] F. Gursoy and V. Karakaya, A Picard-S hybrid type iteration method for solving a differential equation with retarded argument, (2014) arXiv:1403.2546v2.

[15] S. Ishikawa, Fixed points by new iteration method, Proc. Amer. Math. Soc. 149, (1974), 147-150.

[16] C. Izuchukwu, K. O. Aremu, A. A. Mebawondu, O.T. Mewomo, A viscosity iterative technique for equilibrium and fixed point problems in a Hadamard space, Appl. Gen. Topol., 20 (1), (2019), 193-210.

[17] C. Izuchukwu, A. A. Mebawondu, K. O. Aremu, H. A. Abass, O. T. Mewomo, Viscosity iterative techniques for approximating a common zero of monotone operators in an Hadamard space, Rend. Circ. Mat. Palermo II, 69 (2), (2020), 475-495.

[18] C. O Imoru, M.O Olantiwo, On the stability of Picard and Mann iteration processes, Carpath. J. Math. 19 (2), (203), 155-160.

[19] N. Kadioglu and I. Yildirim, Approximating fixed points of non-expansive mappings by faster iteration process, arXiv:1402.6530v1 [math.FA] (2014)

[20] V. Karakaya, V., Atalan, Y. and K. Dogan, On fixed point result for a three steps iteration process in Banach space, Fixed Point Theory, 18 (2), (2017), 625-640.

[21] S.H. Khan, T.O. Alakoya, O.T. Mewomo, Relaxed projection methods with self-adaptive step size for solving variational inequality and fixed point problems for an infinite family of multivalued relatively nonexpansive mappings in Banach spaces, Math. Comput. Appl., 25, (2020), Art. 54, 25 pp.

[22] M. S. Khan, M. Swaleh, and S. Sessa, Fixed point theorems by altering distances between the points, Bull. Austral. Math. Soc., 30 (1), (1984), 1-9.

[23] W. A. Kirk, A fixed point theorem for mappings which do not increase distances, Amer. Math. Monthly 72 (1965), 1004-1006.

[24] W. R. Mann, Mean value methods in iteration, Proc. Amer. Math. Soc. 4, (1953), 506-510.

[25] A. A. Mebawondu, C. Izuchukwu, H. A. Abass and O. T. Mewomo, Some results on generalized mean nonexpansive mapping in complete metric space, Bol. Soc. Paran. Mat. (2019), (Accepted).

[26] A. A. Mebawondu, O.T. Mewomo, Some fixed point results for TAC-Suzuki contractive mappings, Commun. Korean Math. Soc. 34 (4), (2019), 1201-1222.

[27] A.A. Mebawondu, C. Izuchukwu, K.O. Aremu, O.T. Mewomo, Some fixed point results for a generalized TAC-Suzuki-Berinde type F-contractions in b-metric spaces, Appl. Math. E-Notes 19 (2019), 629-653.

[28] S. Moradi, Kannan fixed point theorem on complete metric spaces and on generalized metric spaces depended on another function, arXiv:0903.1577v1 [math.FA].

[29] K. Nakprasit, Mean nonexpansive mappings and Suzuki-generalized nonexpansive mappings, J. nonlinear Anal. Optimization, 1(1), (2010), 93-96.

[30] M. A. Noor, New approximation schemes for general variational inequalities, J. Math. Anal. Appl. 251, (2000) 217-229.

[31] G. N Ogwo, C. Izuchukwu, K.O. Aremu, O. T. Mewomo, A viscosity iterative algorithm for a family of monotone inclusion problems in an Hadamard space, Bull. Belg. Math. Soc. Simon Stevin 27 (1), (2020), 127-152.

[32] G.N. Ogwo, C. Izuchukwu, K.O. Aremu, O.T. Mewomo, On $\theta$-generalized demimetric mappings and monotone operators in Hadamard spaces, Demonstr. Math. 53 (1), (2020), 95-111.

[33] Z. Opial, Weak convergence of the sequence of the successive approximation for nonexapansive mapping, Bull. Amer. Math. Soc. 73, 591-597.

[34] W. Phuengrattana, S. Suantai, On the rate of convergence of Mann, Ishikawa, Noor and SPiterations for continuous functions on an arbitrary interval, J. Comput. Appl. Math., 235 (2011), 3006-3014.

[35] B. E. Rhoades, Some theorems on weakly contractive maps, Nonlinear Anal.: Theory, Methods Appl., 47(4), (2001), 2683-2693.

[36] J. Schu, Weak and strong convergence to fixed points of asymptotically nonexpansive mappings, Bull. Austral. Math. Soc. 43 (1), (1991), 153-159.

[37] T. Suzuki, Fixed point theorems and convergence theorems for some generalized nonexpansive mappings, J. Math. Anal. Appl. 340, (2008), 1088-1095. 
[38] A. Taiwo, T.O. Alakoya, O.T. Mewomo, O.T., Halpern-type iterative process for solving split common fixed point and monotone variational inclusion problem between Banach spaces, Numer. Algorithms, (2020), DOI: 10.1007/s11075-020-00937-2.

[39] A. Taiwo, L.O. Jolaoso, O.T. Mewomo, A. Gibali, On generalized mixed equilibrium problem with $\alpha-\beta-\mu$ bifunction and $\mu-\tau$ monotone mapping, J. Nonlinear Convex Anal., 21 (6), (2020), 1381-1401.

[40] B. S. Thakur, D. Thakur and M. Postolache, A new iterative scheme for numerical reckoning fixed points of Suzuki's generalized nonexpansive mappings, App. Math. Comp., 275 (2016), 147-155.

[41] G. C. Ugwunnadi, C, Izuchukwu, O. T. Mewomo,Strong convergence theorem for monotone inclusion problem in $C A T(0)$ spaces, Afr. Mat. 30 (1-2), (2019), 151-169

[42] K. Ullah and M. Arshad, Numerical reckoning fixed points for Suzuki generalized nonexpansive mappings via new iteration process, Filomat, 32(1), (2018), 187-196.

[43] C. X. Wu and L.J. Zhang, Fixed points for mean non-expansive mappings, Acta Math. Appl. Sinica, 23 (3),(2007), 489-494.

[44] S. Zhang, About fixed point theory for mean nonexpansive mapping in Banach spaces, Journal of Sichuan University 2 (1975), 67-68.

[45] J. Zhou and Y. Cui, Fixed point theorems for mean nonexpansive mappings in CAT (0) spaces, Numer. Funct. Anal. Optim. 36 (9)(2015), 1224-1238.

[46] Z. Zuo, Fixed-point theorems for mean nonexpansive mappings in Banach spaces, Abstract Applied Anal. 2014, (2014), 1-6.

A. A. Mebawondu: 216028272@stu.ukzn.ac.za, dele@aims.ac.za

School of Mathematics, Statistics and Computer Science, University of KwaZulu-Natal, Durban, South Africa

C. Izuchukwu: izuchukwuc@ukzn.ac.za, izuchukwu_c@yahoo.com

School of Mathematics, Statistics and Computer Science, University of KwaZulu-Natal, Durban, South Africa

K. O. Oyewole: 217079141@stu.ukzn.ac.za, oyewoleolawalekazeem@gmail.com

O. T. Mewomo: mewomoo@ukzn.ac.za

Received 30/07/2019; Revised 31/10/2020 